\title{
Peertechz
}

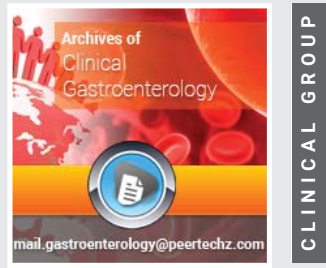

\section{A Case of Rapunzel Syndrome}

\section{Krisztina Csuzi ${ }^{1 *}$, Orsolya Boda ${ }^{2}$, Robert Neumann ${ }^{2}$ and Gergely Peter Toth ${ }^{1}$}

1Pediatric Department, Elisabeth Hospital, Sopron, Hungary

${ }^{2}$ Department of Surgery, Elisabeth Hospital, Sopron, Hungary
Received: 06 July, 2020

Accepted: 25 July, 2020

Published: 27 July, 2020

*Corresponding author: Krisztina Csuzi, MD, Pediatrician, Medical Doctor, Pediatric Department, Elisabeth Hospital, Sopron, Hungary, Tel: +36204405241; E-mail: krisztina.csuzi@gmail.com

Keywords: Bezoar; Rapunzel syndrome; Thrichophagia; Abdominal pain

https://www.peertechz.com

\section{Abstract}

Trichobezoar is a concretion of chewing and swallowing hair or any other indigestible materials that accumulate in the gastrointestinal tract. Rapunzel syndrome refers to a rare condition when a gastric trichobezoar extends into the small bowel. We describe the case of a 16-year-old female who presented with chronic abdominal pain, loss of appetite and weight loss. Based on her past medical history, trichophagia has already been revealed at preschool age. Imaging tests indicated a large filling of the stomach. Upper gastrointestinal endoscopy showed a large trichobezoar in the stomach with prolonga on through the pylorus. The patient underwent exploratory laparotomy and the trichobezoar was removed. Upper gastrointestinal endoscopy is the preferred modality for diagnosis and in most cases the treatment is surgical.

\section{Introduction}

Bezoars are intraluminal accumulations of indigestible material. They have been classified into phytobezoars (comprised of vegetable and fruit residue), lactobezoars (comprised of milk residue), pharmacobezoars (comprised of pills and capsules) and trichobezoars (an accumula on of hair), according to their dominant composition [1]. Trichobezoars are common in patients with mental retardation, psychiatric disorders or personality disorders such as trichophagia and trichotillomania.

Rapunzel syndrome is a rare condition when a gastric trichobezoar extends into the small bowel increasing the risk of complications such as obstruction, perforation and peritonis [2]. The syndrome is named a er the heroine of a German fairy tale written by the Grimm Brothers and first published in 1812 . The fairy tale is about a young princess with a long golden hair imprisoned by a witch in a tall tower with neither stairs nor a door [1]. One day, a prince rode through the forest and heard Rapunzel singing from the tower. After a while, they fell in love with each other, the princess lowered her long hair to the ground from her window, so the prince could climb up and rescue her.

\section{Case report}

A 16-year-old female was referred to our Paediatric Department with abdominal pain for two years, loss of appetite and weight loss for a month. Two years earlier the patient was treated with acute pancreatitis in another hospital. During the treatment abdominal ultrasound and MRI scan were taken showing a diffuse parenchymal enlargement. Other laboratory examinations could not clarify the aetiology. Three months later the patient visited the emergency department of the same hospital because of heavy epigastric pain. The examinations excluded acute pancreatitis, her pain was considered gastric hyperacidity and she was proposed to take proton-pump inhibitor. The patient's condition did not improve during medication.

Over time, her complaints were associated with weight loss and loss of appetite. During an examination carried out by the family doctor a palpable firm mass was revealed in the epigastric region. The rest of the physical examination was unremarkable. After that the patient underwent the following investigations. Abdominal ultrasound showed a large-scale echogenic mass in the stomach with dense posterior acoustic shadow. Barium meal test showed intraluminal filling defect with a size of $13 \times 5 \mathrm{~cm}$. Based on her past history, trichophagia was present at preschool age.

The patient was referred to our Department with the above-mentioned symptoms and examination results. In our Department gastroscopy took place and it revealed a huge gastric trichobezoar (Figure 1) with prolongation through the pylorus (Figure 2). 
The patient underwent gastrostomy (Figure 3), with retrieval of the trichobezoar without any surgical complica tions. The stomach-shaped mass measured $20.0 \times 5.0 \times 5.0 \mathrm{~cm}$ (Figure 4) and had a tail of hair extending through the pylorus into the middle part of the duodenum.

According to these symptoms and examination results we expected to find a large bezoar during the gastroscopy but we could not expect that it extended through the pylorus. Because of the large size it was certain that surgical intervention was needed. So the actual outcome of the treating plan was similar to our expected outcome. Since then the patient has been under gastroenterological control.

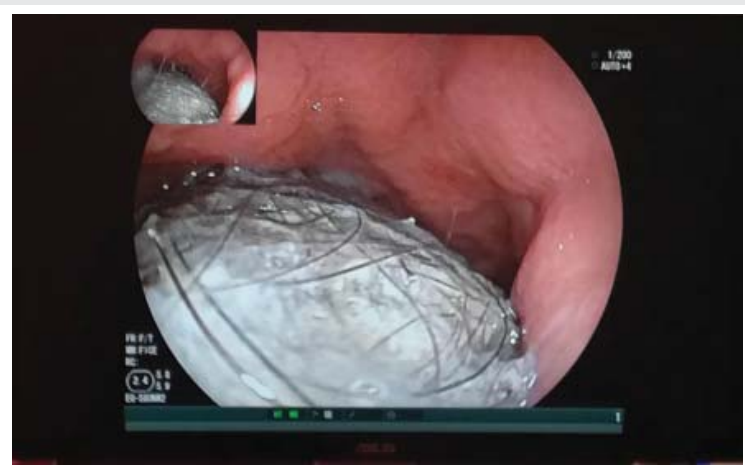

Figure 1: Large trichobezoar in the stomach.

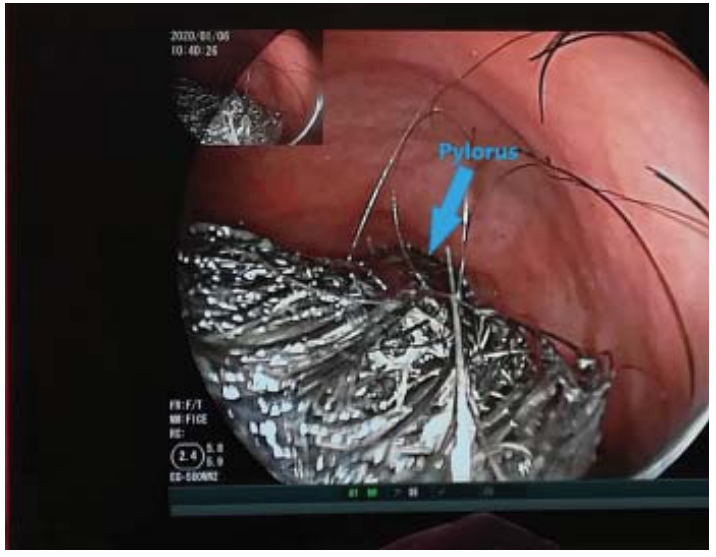

Figure 2: The trichobezoar extends through the pylorus.

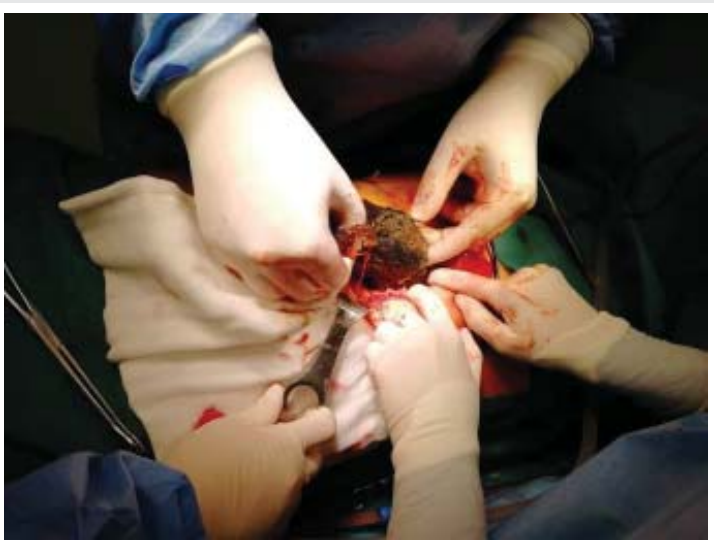

Figure 3: Gastrostomy - removal of the bezoar.

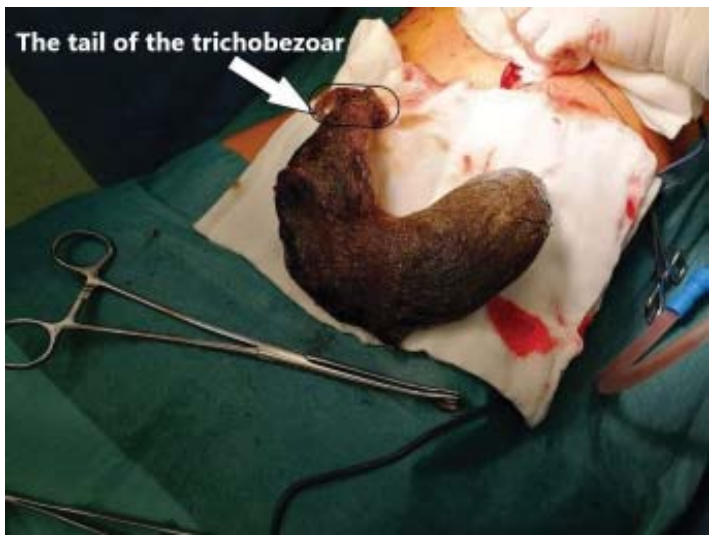

Figure 4: The stomach-shaped trichobezoar with the size of $20.0 \times 5.0 \times 5.0 \mathrm{~cm}$.

This case report has been written with the patient consent and institutional approval.

\section{Discussion}

We have described a rare cause of chronic abdominal pain among children by introducing the case of a 16-year-old female who had a history of trichophagia. The diagnosis was based on the patient's medical history, physical examination, imaging tests and upper gastrointestinal endoscopy. The bezoar was removed by exploratory laparotomy. Rapunzel syndrome is a rare condition in paediatric population. During the differential diagnosis of chronic abdominal pain, we have to think about Rapunzel syndrome if there is a history of trichotillomania or trichophagia.

Trichobezoar is a concretion of chewing and swallowing hair that accumulates in the stomach and fails to pass through the intestines. If it extends into the small intestine, it is referred to as Rapunzel syndrome. The syndrome was first described by Vaughan, et al. in 1968 [3,4].

It is a very rare entity in paediatric population, most commonly affecting women under the age of 30, mainly associated with psychiatric conditions [5].

Symptoms could include abdominal pain, loss of appetite, nausea/vomiting, and weight loss. Patients can be asymptomatic until the bezoar reaches the point of obstruction. The following complications may occur: gastric ulceration, acute pancreatitis, gastric perforation, obstructive jaundice, complete intestinal obstruction, severe peritonitis $[6,7]$.

Small bezoars can be extracted via endoscopy using various disintegrating techniques, but in most cases a surgical management is needed because of the large size $[8,9]$. Rou tine endoscopy, ultrasonography can be used for detection of recurrence.

\section{References}

1. Kim JS, Nam CW (2013) A Case of Rapunzel Syndrome. Pediatr Gastroentero Hepatol Nutr 16: 127-130. Link: https://bit.ly/2WRhFxZ

2. Nieto JO, Suárez JV, Vergara JJV, Molina JMT (2011) Rapunzel Syndrome. A case report and literature review. Rev Col Gastroenterol 26: 58-60. Link: https://bit.ly/32UDUaq 
3. Vaughan ED, Sawyers JL, Sco HW (1968) The Rapunzel syndrome: An unusual complication of intestinal bezoar. Surgery 63: 339-343. Link: https://bit.ly/2WPm3xJ

4. Finale E, Franceschini P, Danesino C, Barbaglia M, Guala A (2018) Rapunzel syndrome: how to orient the diagnosis. Pediatr Rep 10: 7689. Link: https://bit.ly/30NxxTs

5. Lyons D (2019) Large gastric trichobezoar causing failure to thrive and iron deficiency anaemia in an adolescent girl: a case report emphasising the imaging findings and review of the literature. BJR Case Rep 5: 20180080. Link: https://bit.ly/2OVEoER

6. Jensen AR, Trankiem CT, Lebovitch S, Grewal H (2005) Gastric outlet obstruction secondary to a large trichobezoar. J Pediatr Surg 40: 1364-1365. Link: https://bit.ly/3hwllqv

7. Lalith S, Gopalakrishnan KL, Ilangovan G, Jayajothi A (2017) Rapunze Syndrome. J Clin Diagn Res 11: TD01-TD02. Link: https://bit.ly/30NXx0S

8. Gupta A, Kaur J, Wadhwa N (2017) Rapunzel syndrome in a seven year old female. Turk J Pediatr 59: 598-600. Link: https://bit.ly/2WRgE99

9. Fallon SC, Slater BJ, Larimer EL, Brandt ML, Lopez ME (2013) The surgical management of Rapunzel syndrome: a case series and literature review. J Pediatr Surg 48: 830-834. Link: https://bit.ly/3eT6c7u

\section{Discover a bigger Impact and Visibility of your article publication with}

\section{Peertechz Publications}

\section{Highlights}

* Signatory publisher of ORCID

* Signatory Publisher of DORA (San Francisco Declaration on Research Assessment)

* Articles archived in worlds' renowned service providers such as Portico, CNKI, AGRIS, TDNet, Base (Bielefeld University Library), CrossRef, Scilit, J-Gate etc.

* Journals indexed in ICMJE, SHERPA/ROMEO, Google Scholar etc.

* OAI-PMH (Open Archives Initiative Protocol for Metadata Harvesting)

* Dedicated Editorial Board for every journal

* Accurate and rapid peer-review process

* Increased citations of published articles through promotions

* Reduced timeline for article publication

Submit your articles and experience a new surge in publication services (https://www.peertechz.com/submission).

Peertechz journals wishes everlasting success in your every endeavours.

Copyright: @ 2020 Csuzi K, et al. This is an open-access article distributed under the terms of the Creative Commons Attribution License, which permits unrestricted use distribution, and $\mathrm{r}$ eproduction in any medium, provided the original author and source are credited. 